\title{
Supressão de plantas daninhas pelo efeito da cobertura com Pennisetum purpureum e esterco de aves na cultura do gergelim
}

\author{
Morgana de Matos Ortolan ${ }^{1}$, Ana Paula Werkhausen Witter ${ }^{1}$, Marcos André Nohatto² e Airton Luiz Bortoluzzi
}

\begin{abstract}
Resumo - O gergelim (Sesamum indicum) apresenta grande potencial para cultivo no Sul catarinense, mas a ampliação no plantio é dificultada por problemas de manejo, especialmente relacionados ao controle de plantas daninhas. Diante disso, o objetivo do trabalho foi avaliar o efeito do esterco de aves e de diferentes camadas de cobertura de capim-elefante (Pennisetum purpureum) na supressão de plantas daninhas e componentes de produção do gergelim. Os tratamentos foram dispostos em esquema fatorial $(3 \times 2)$, sendo o fator $A$ composto por diferentes espessuras de cobertura vegetal $(0,2$ e $4 \mathrm{~cm})$ e o fator $B$, por doses de esterco de aves $\left(0\right.$ e $\left.3 \mathrm{~kg} \mathrm{~m}^{-2}\right)$. As variáveis avaliadas foram: identificação e fitomassa seca da parte aérea das plantas daninhas aos 15 e 30 dias após transplante (DAT) das mudas e contagem do número de cápsulas e fitomassa seca da cultura. $O$ incremento do nível de palha no solo reduz a fitomassa seca da parte aérea das plantas daninhas e aumenta o número de cápsulas e fitomassa seca do gergelim, enquanto a adubação com esterco de aves $\left(3 \mathrm{~kg} \mathrm{~m}^{-2}\right)$ não interfere nos componentes avaliados.
\end{abstract}

Termos para indexação: Sesamum indicum; cobertura; capim-elefante.

\section{Weed suppression by the effect of the cover with Pennisetum purpureum and poultry manure in Sesame}

Abstract - Sesame (Sesamum indicum) has great potential for cultivation in the South of Santa Catarina, but the expansion of the crops is hindered by problems in management, especially due to weed infestation. Therefore, the objective of this study was to evaluate the effect of poultry manure and different layers of Napier grass (Pennisetum purpureum) on supressing weeds and sesame production components. The treatments were arranged in a factorial scheme $(3 \times 2)$, with factor A composed of different thickness of vegetation cover $(0,2$ and $4 \mathrm{~cm})$, and factor $B$ of dosages of poultry manure $\left(0 \mathrm{and} 3 \mathrm{~kg} \mathrm{~m}^{-2}\right)$. The evaluated variables were: identification and dry phytomass of the weed aerial part at 15 and 30 days after seedling transplanting (DAT), and number of capsules and dry phytomass of the crop. The increase in the level of hay in the soil reduces the weed dry phytomass, increases the number of capsules and the dry phytomass of sesame, while the fertilization of poultry manure $(3 \mathrm{~kg}$ $\mathrm{m}^{-2}$ ) does not interfere with the evaluated components.

Index terms: Sesamum indicum; cover; Napier grass.

\section{Introdução}

O gergelim (Sesamum indicum L.) é uma planta pertencente à família Pedaliaceae, considerada mundialmente como uma das oleaginosas mais cultivadas (QUEIROGA \& SILVA, 2008). O Brasil caracteriza-se como pequeno produtor de gergelim, com 15 mil toneladas produzidas numa área de 24 mil hectares (PERIN et al., 2010), sendo que a produção nacional se concentra em Goiás, São Paulo, Mato Grosso, Triângulo Mineiro e Nordeste (BARROS et al., 2001).

É cultivado especialmente para produção de grãos para extração de óleo e outros produtos alimentícios, mas também tem uso comprovado na indústria farmacêutica. Além disso, pode ser empregado como cultura-armadilha para mosca-branca e controle de formigascortadeiras. Essa cultura se insere nos sistemas tradicionais (convencional e plantio direto) e no sistema de produção agroecológico. Pela tolerância à seca e pela facilidade de produção, destaca-se ainda pela opção de cultivo em sucessão, rotação e consorciação com outras culturas, o que desperta o interesse dos produtores que buscam alternativas de produção familiar (PERIN et al., 2010).

Estratégias de manejo da cultura têm sido estudadas para essa oleagino- sa, como espaçamento e densidade de semeadura, adubação mineral e seleção de cultivares com alto teor de óleo (ÁVILA \& GRATEROL, 2005). Apesar dessas informações, em face de perspectiva de exploração econômica da cultura, tornam-se necessários mais estudos, especialmente em áreas de carência de conhecimento, como a adubação orgânica e o manejo de plantas daninhas.

Redução significativa na população destas últimas e incremento na produção de gergelim foram observados por Al-Eqaili et al. (2016) com o cultivo sob palha de trigo e sem revolvimento quando em comparação com o cultivo sem palhada na superfície e com revol-»

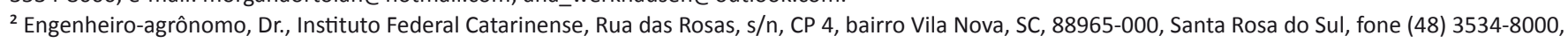
e-mail: marcos.nohatto@ifc.edu.br; airton.bortoluzzi@ifc.edu.br. 
vimento do solo. Os autores constataram $50 \%$ de aumento na produtividade de gergelim no sistema sob mulching de palha de trigo em comparação com o sistema de preparo com incorporação da palhada.

A produtividade média da oleaginosa no Brasil é considerada muito baixa (650kg ha-1) (PERIN et al., 2010). Porém, valores superiores já foram obtidos, como $2.000 \mathrm{~kg} \mathrm{ha}^{-1}$ (PINTO et al., 2014). Ao avaliar diferentes fontes de adubação orgânica, Euba Neto et al. (2016) verificaram produtividades de 920 (testemunha) a $1.350 \mathrm{~kg} \mathrm{ha}^{-1}$, indicando resposta positiva da cultura à adubação. Dessa forma, acredita-se que o uso de esterco animal associado à cobertura morta auxilia no manejo de plantas daninhas, potencializando a produtividade do gergelim, além de demonstrar alternativa para eliminação do uso de herbicidas na cultura.

Nesse contexto, este trabalho tem como objetivo avaliar o efeito do esterco de aves e diferentes camadas de cobertura de capim-elefante (Pennisetum purpureum) na supressão de plantas daninhas e componentes de produção do gergelim.

\section{Material e métodos}

O experimento foi conduzido em área experimental com as coordenadas geográficas de latitude $29^{\circ} 05^{\prime} 46.5^{\prime \prime}$ sul e longitude $49^{\circ} 48^{\prime} 42.4^{\prime \prime}$ oeste, pertencente ao Instituto Federal Catarinense, campus Santa Rosa do Sul, durante o período de dezembro de 2016 a maio de 2017.

As unidades experimentais foram canteiros com $1,8 \mathrm{~m}$ de largura por $1,5 \mathrm{~m}$ de comprimento $\left(2,7 \mathrm{~m}^{2}\right)$ em solo gleissolo melânico, apresentando as seguintes características químicas: $\mathrm{pH}$ em água $=6,5 ; \% \mathrm{MO}$ (matéria orgânica) = 2,6; fósforo $(\mathrm{P})=52 \mathrm{mg} \mathrm{dm}^{-3}$; potássio $(\mathrm{K})=0,9 \mathrm{cmolc} \mathrm{dm}^{-3}$; cálcio (Ca) trocável $=4,4 \mathrm{cmolc} \mathrm{dm}^{-3}$; magnésio $(\mathrm{Mg})$ trocável

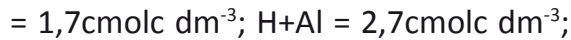
CTC (capacidade de troca de cátions) =9,7; alumínio (Al) trocável $=0 \mathrm{cmolc}$ $\mathrm{dm}^{-3}$. O gergelim foi cultivado em espaçamento de $0,30 \mathrm{~m}$ entre plantas e $0,25 m$ entre linhas.

Os tratamentos foram dispostos em delineamento em blocos ao acaso, com três repetições e em esquema fatorial $(3 \times 2)$, sendo o fator A composto por diferentes espessuras de capimelefante (Pennisetum purpureum) triturado (0, 2 e $4 \mathrm{~cm})$ e o fator B, por doses de esterco de aves adicionadas ao solo (0 e $3 \mathrm{~kg} \mathrm{~m}^{-2}$ ) (Figura 1 ). O esterco de aves curtido utilizado era composto por $1,5 \%$ nitrogênio total; $20 \%$ carbono orgânico; 25\% umidade; pH 8,0; e CTC $340 \mathrm{mmol} \mathrm{c} \mathrm{kg}^{-1}$, sendo aplicado na superfície do solo (sem incorporação) nas unidades experimentais designadas no momento do transplante das mudas de gergelim. Na sequência, o resíduo vegetal foi adicionado ao solo na quantidade de 2,5 e $5 \mathrm{~kg} \mathrm{~m}^{-2}$ de capim-elefante triturado, formando camadas de aproximadamente 2 e $4 \mathrm{~cm}$, respectivamente.
As mudas foram obtidas em ambiente protegido pelo cultivo de sementes em bandejas plásticas (volume de $180 \mathrm{~mL} /$ célula). O substrato para a produção foi constituído de $25 \%$ de casca de arroz carbonizada $+30 \%$ de um solo vermicomposto $+20 \%$ de um solo oxídico argiloso de origem do basalto $+25 \%$ de esterco de bovinos. As mudas foram irrigadas por ascensão capilar, tendo o fundo das células das bandejas imersas em $2 \mathrm{~cm}$ de água e sendo mantidas até o tamanho aproximado de $15 \mathrm{~cm}$.

Aos 15 e 30 dias após o transplante (DAT) das mudas e instalação dos tratamentos, em área de $0,16 \mathrm{~m}^{2}$ (quadrado metálico de $0,40 \times 0,40 \mathrm{~m}$ posicionado no interior da parcela), foram feitos a identificação das espécies de plantas daninhas e o corte destas rente à super-
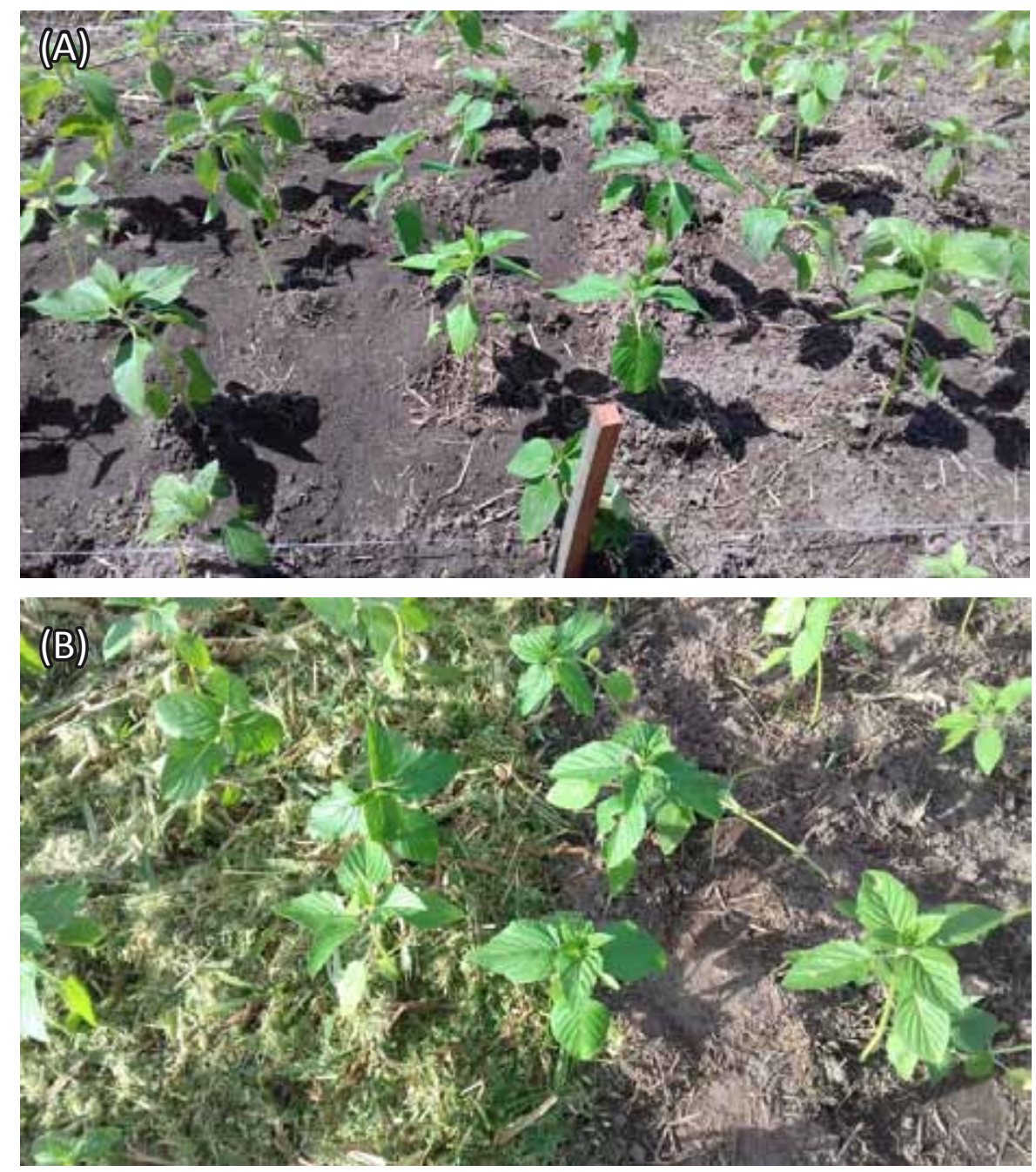

Figura 1 - Unidades experimentais com esterco de aves (A) e capim-elefante (Pennisetum purpureum) triturado (B)

Figure 1 - Experimental units with poultry manure $(A)$ and elephantgrass (Pennisetum purpureum) crushed (B) 
fície do solo para determinação da fitomassa seca da parte aérea. Essa variável foi obtida pela secagem da parte aérea das plantas daninhas em estufa a $65^{\circ} \mathrm{C}$ por 72 horas.

Aos 50 DAT foram efetuadas a contagem do número de cápsulas e a retirada das folhas de cinco plantas escolhidas aleatoriamente dentro da unidade experimental. As folhas foram submetidas à secagem em procedimento semelhante ao descrito anteriormente, com intuito de avaliar a fitomassa seca da parte aérea da cultura.

Os dados obtidos passaram por análise de variância ( $p \leq 0,05)$. No caso de ser constatada significância estatística, foi feita comparação de médias pelo teste de Tukey $(p \leq 0,05)$ utilizando o programa Assistat.

\section{Resultados e discussão}

Para todas as variáveis, não houve interação entre os fatores estudados ( $p \leq 0,05$ ). Contudo, observou-se efeito principal do fator nível de palha para a variável fitomassa seca das plantas daninhas nas duas épocas de avaliação (Tabela 1). Essa variável foi menor quando houve a utilização de palha de capim-elefante triturada sob o solo, independentemente da quantidade (Tabela 1).

Esse comportamento também foi observado por outros autores com o uso de coberturas vegetais, como por Moraes et al. (2010), que utilizaram paIhas de nabo-forrageiro (Raphanus sativus L.) e canola (Brassica napus L.) sobre o solo para reduzir o crescimento das plantas de picão-preto (Bidens sp.). A respeito da mesma planta daninha, Correia et al. (2006) verificaram a diminuição do número de plântulas com o uso das palhas de sorgo (Sorghum bicolor $x$ S. sudanensis 'Cober Exp') $\left(5,5 \mathrm{t} \mathrm{ha}^{-1}\right)$, de capim-pé-de-galinha (Eleusine coracana L.) $(3,0$ e 5,5t ha-1) e de braquiária (Brachiaria brizantha) $\left(3,0 \mathrm{t} \mathrm{ha}^{-1}\right)$.

A explicação para os resultados possivelmente decorre de efeitos físicos, químicos e/ou biológicos que a cobertura proporciona. O efeito físico da cobertura é muito importante na regulação da germinação e na taxa de sobrevivência das plântulas de algumas espécies de

Tabela 1 - Fitomassa seca da parte aérea das plantas daninhas (gramas) aos 15 e 30 DAT das mudas de gergelim e instalação dos tratamentos, em função da adubação de cama de aves e níveis de palha de capim-elefante triturado

Table 1 - Phytomass drought shoots of weeds (grams) at 15 and 30 DAT of sesame seedlings and installation of treatments, depending on the chicken litter fertilization and elephant grass crushed straw levels

\begin{tabular}{ccc|}
\hline & 15 DAT & 30 DAT \\
\hline Adubação $\left(\mathrm{kg} \mathrm{m}^{-2}\right)$ & & \\
\hline 0 & $1,22 \mathrm{a}^{1}$ & $2,42 \mathrm{a}$ \\
3 & $1,48 \mathrm{a}$ & $2,83 \mathrm{a}$ \\
\hline DMS & 1,60 & 1,93 \\
Palha (cm) & & \\
0 & $3,80 \mathrm{a}$ & $6,48 \mathrm{a}$ \\
\hline 2 & $0,20 \mathrm{~b}$ & $0,65 \mathrm{~b}$ \\
\hline 4 & $0,04 \mathrm{~b}$ & $0,74 \mathrm{~b}$ \\
\hline DMS & 2,41 & 2,91 \\
\hline CV (\%) & 23,41 & 25,19 \\
\hline
\end{tabular}

${ }^{1}$ Médias seguidas por mesma letra minúscula na coluna não diferem pelo teste de Tukey $(p \leq 0,05)$.

plantas daninhas. As consequências sobre o processo germinativo podem ser exemplificadas com a redução da germinação de sementes fotoblásticas positivas, das que requerem determinado comprimento de onda e das que necessitam de grande amplitude de variação térmica para inibir o processo germinativo. O efeito físico da palha também a redução das chances de sobrevivência das plântulas de ervas daninhas com pequena quantidade de reservas nos diásporos (CORREIA \& DURIGAN, 2004; PITELLI \& DURIGAN, 2001).

No efeito biológico, a presença da cobertura criará condições para a instalação de uma densa e diversificada microbiocenose na camada superficial do solo. Na composição dessa microbiocenose, há grande quantidade de organismos que podem utilizar sementes de plantas daninhas com fonte de energia para sua multiplicação. De maneira geral, os microrganismos exercem importantes funções de deterioração e perda da viabilidade dos diversos tipos de propágulos no solo. Além disso, deve ser considerado que a cobertura proporciona um ambiente seguro para alguns predadores de sementes e plântulas, como roedores, insetos e outros pequenos animais (ALVES \& PITELLI, 2001).

Na parte química, o processo de decomposição da palha na superfície do solo libera, gradativamente, uma série de compostos orgânicos denominados aleloquímicos, que também podem in- terferir diretamente na germinação e emergência das plantas daninhas (CORREIA \& DURIGAN, 2004). Estudos têm demonstrado o efeito alelopático do capim-elefante, reduzindo a germinação de Hedyotis verticillata, Leptochloa chinensis (NORHAFIZAH et al., 2012) e Eleusine indica, sendo que compostos fenólicos estão envolvidos no efeito químico sobre as daninhas (ISMAIL et al., 2015).

Para as variáveis fitomassa seca/ planta e número de cápsulas/planta, também se observou apenas o efeito principal do fator nível de palha (Tabela 2 ), indicando que possivelmente a dose de cama de aves utilizada não foi suficiente para alterar de forma significativa os fatores estudados. Infere-se que a boa fertilidade no local do experimento tenha contribuído para tais resultados, uma vez que por várias safras o manejo desse solo tem sido feito em sistema de base ecológica, caracterizado por não revolvimento do solo e manutenção da matéria orgânica. Outro fator que pode estar relacionado à ausência de diferenças significativas em função da dose de cama de aves utilizada possivelmente deve-se à própria rusticidade da cultura. Estudo a campo conduzido por Perin et al. (2010) verificou que não houve efeito significativo da adubação para o número de vagens por planta, peso de matéria seca e produtividade de grãos de gergelim, reforçando a baixa resposta que a cultura apresenta à adubação, • 
Tabela 2 - Fitomassa seca (gramas) e número de cápsulas da cultura avaliada aos 50 DAT das mudas de gergelim e instalação dos tratamentos, em função da adubação de cama de aves e níveis de palha de capim-elefante triturado

Table 2 - Dry weight (grams) and number of culture capsules assessed at 50 days of sesame seedlings and installation of treatments, depending on the chicken litter fertilization and elephant grass crushed straw levels

\begin{tabular}{ccc} 
& $\begin{array}{c}\text { Fitomassa } \\
\text { seca planta }{ }^{-1}(\mathrm{~g})\end{array}$ & $\begin{array}{c}\text { Número de cápsulas } \\
\text { planta }^{-1}\end{array}$ \\
\hline Adubação $\left(\mathrm{kg} \mathrm{m}^{-2}\right)$ & & \\
\hline 0 & $16,44 \mathrm{a}^{1}$ & $13,71 \mathrm{a}$ \\
3 & $20,28 \mathrm{a}$ & $11,40 \mathrm{a}$ \\
\hline DMS & 4,37 & 2,46 \\
\hline Palha $(\mathrm{cm})$ & $13,34 \mathrm{~b}$ & $8,10 \mathrm{c}$ \\
\hline 0 & $18,16 \mathrm{ab}$ & $11,90 \mathrm{~b}$ \\
\hline 2 & $23,57 \mathrm{a}$ & $17,67 \mathrm{a}$ \\
\hline 4 & 6,59 & 3,71 \\
\hline DMS & 22,69 & 18,67 \\
\hline
\end{tabular}

Médias seguidas por mesma letra minúscula na coluna não diferem pelo teste de Tukey $(p \leq 0,05$

também verificada neste trabalho.

Ao analisar as variáveis da planta, percebe-se, em geral, que houve incremento da fitomassa seca e do número de cápsulas do gergelim quando a planta foi submetida a maior quantidade de palha, comparado com a testemunha (Tabela 2). Tais resultados estão relacionados com a menor presença de ervas daninhas observada nesses tratamentos, o que possivelmente reduziu a competição por recursos entre plantas, favorecendo o desenvolvimento da cultura. Estudo conduzido por ljlal et al. (2011) reforça essa afirmativa, uma vez que foi verificada redução de $12,4 \%$ na produtividade do gergelim quando submetido à interferência de plantas daninhas entre a terceira e a sexta semana após emergência da cultura. Além disso, supõe-se que o fato de triturar o capim-elefante também facilitou a decomposição vegetal, aumentando a rapidez na liberação de nutrientes ao solo e o aproveitamento pelo gergelim.

Ao avaliar os efeitos de resíduos de aveia-preta (Avena strigosa) sobre a densidade de papuã (Brachiaria plantaginea) e a produtividade da soja, Theisen et al. (2000) verificaram que níveis dos tratamentos experimentais experimental treatments tados obtidos em nosso experimento, apesar de as espécies utilizadas serem diferentes.

Não foi realizada a contagem de plântulas das espécies daninhas, porém sua identificação permitiu estabelecer algumas relações empíricas do efeito da cobertura e/ou do esterco sobre a presença de determinadas espécies (Tabela 3). Observou-se que o incremento no nível de palha reduz a diversidade de plantas daninhas presentes na unidade amostrada (quadro de 0,40 $\times 0,40 \mathrm{~m}$ posicionado no interior da parcela), porém não foi suficientemente capaz para suprimir o estabelecimento de Cyperus sp. Tais daninhas apresentam ciclo C4 de fixação de carbono (KISSMANN et al., 1997), atribuindo vantagem fotossintética em condições de altas temperatura e luminosidade, frequentemente relatadas na região em que foi conduzido o experimento. Além disso, essas são plantas vigorosas e prolíferas, que se reproduzem tanto por sementes quanto vegetativamente. Durigan (1991) relata a produção de 8.700 tubérculos $\mathrm{m}^{-2} \mathrm{da}$

Tabela 3 - Relação das espécies de plantas daninhas presentes no experimento em função

Table 3 - Relation of the weed species present in the experiment as a function of the

\begin{tabular}{|c|c|c|}
\hline $\begin{array}{l}\text { Adubação } \\
\left(k^{-2} ~ m^{-2}\right.\end{array}$ & $\begin{array}{l}\text { Nível de } \\
\text { palha }(\mathrm{cm})\end{array}$ & $\begin{array}{l}\text { Espécies daninhas relatadas (nome científico e } \\
\text { popular) }\end{array}$ \\
\hline 0 & 0 & $\begin{array}{l}\text { Ipomoea sp. (corda-de-viola), Cyperus sp. (tiririca), } \\
\text { Digitaria sp. (milhã), Brachiaria plantaginea } \\
\text { (papuã), Amaranthus sp. (caruru), Portulaca } \\
\text { oleracea (beldroega), Galinsoga parviflora (picão- } \\
\text { branco), Commelina sp. (trapoeraba) e Euphorbia } \\
\text { heterophylla (leiteira) }\end{array}$ \\
\hline 0 & 2 & $\begin{array}{l}\text { Ipomoea sp., Cyperus sp., Digitaria sp.; Amaranthus } \\
\text { sp., Portulaca oleracea, Galinsoga parviflora, } \\
\text { Euphorbia heterophylla e Oxalis sp. (trevinho) }\end{array}$ \\
\hline 0 & 4 & Cyperus sp. e Digitaria sp. \\
\hline 3 & 0 & $\begin{array}{l}\text { Ipomoea sp., Cyperus sp., Digitaria sp., Brachiaria } \\
\text { plantaginea, Amaranthus sp. e Portulaca oleracea }\end{array}$ \\
\hline 3 & 2 & $\begin{array}{l}\text { Ipomoea sp., Digitaria sp., Amaranthus sp. e } \\
\text { Euphorbia heterophylla }\end{array}$ \\
\hline 3 & 4 & Cyperus sp. e Commelina sp. \\
\hline
\end{tabular}


espécie Cyperus rotundus, indicando a múltipla capacidade de reprodução e, por consequência, a dificuldade para seu controle.

Não foi descartada no estudo a possibilidade do efeito selecionador da paIhada sobre as espécies daninhas, por mecanismos ainda desconhecidos, mas possivelmente relacionados à natureza física, química e biológica da cobertura vegetal. Estudo conduzido por Correia \& Durigan (2004) apresentou evidências disso, constatando que o revestimento do solo com 5, 10 e 15t ha-1 de palha de cana inibiu a emergência de plântulas das espécies $B$. decumbens e $S$. spinosa. No entanto, a presença da cobertura incrementou a emergência de plântulas de I. quamoclit, o que indica seu efeito selecionador sobre a comunidade infestante.

A relação entre aumento da cobertura, redução da quantidade e da diversidade de plantas daninhas e aumento da produtividade na cultura foi evidente após avaliação dos resultados. Essa associação é bem conhecida no ambiente acadêmico, porém, na prática, ainda não tem sido amplamente explorada. Considerando que a cultura do gergelim não possui herbicidas registrados, trata-se de estratégia fundamental para o manejo de plantas daninhas, favorecendo o potencial produtivo da cultura, além de apresentar efeito positivo na redução do banco de sementes de espécies daninhas para as safras seguintes e no aumento da qualidade do solo e de preservar um sistema de base agroecológica sem o uso de herbicidas.

\section{Conclusão}

O incremento do nível de palha reduz a fitomassa seca da parte aérea das plantas daninhas e aumenta o número de cápsulas e da fitomassa seca do gergelim, enquanto a adubação com esterco de aves curtido $\left(3 \mathrm{~kg} \mathrm{~m}^{-2}\right)$ não interfere nos componentes avaliados.

\section{Referências}

AL-EQAILI, S.N.M.; LAHMOD, N.R.; ESHKAN$\mathrm{DI}, \mathrm{O} . \mathrm{H}$. Weed management in sesame field (Sesamum indicum L.) using wheat straw and tillage or no tillage systems. American Journal of Agricultural and Biological Sciences, Amsterdam, v. 9, n. 2, p. 36-38, 2016.

ALVES, P.L.C.A.; PITELLI, R.A. Manejo ecológico de plantas daninhas. Informe Agropecuário, Belo Horizonte, v. 22, n. 212, p. 29-39, 2001.

ÁVILA, J.M.; GRATEROL, Y.E. Planting date, row spacing and fertilizer effects on growth and yield of sesame (Sesamum indicum L.). Bioagro, Barquisimeto, v. 17, n. 1, p. 35-40, 2005.

BARROS, M.A.L.; SANTOS, R.B.; BENATI, T.; FIRMINO, P.T. Importância econômica e social. In: BELTRÃO, N.M.; VIEIRA, D.J. (Ed.). 0 agronegócio do gergelim no Brasil. Brasília: Embrapa, 2001. p. 21-35.

CORREIA, N.M.; DURIGAN, J.C. Emergência de plantas daninhas em solo coberto com palha de cana-de-açúcar. Planta Daninha, Viçosa, v. 22, n. 1, p. 11-17, 2004.

CORREIA, N.M.; DURIGAN, J.C.; KLINK, U.P. Influência do tipo e da quantidade de resíduos vegetais na emergência de plantas daninhas. Planta Daninha, Viçosa, v. 24, n. 2, p. 245-253, 2006

DURIGAN, J.C. Manejo da tiririca (Cyperus rotundus $\mathrm{L}$.) antes e durante a implantação da cultura de cana-de-açúcar (Saccharum spp.). 1991. 336 f. Tese (Livre-Docência em Agronomia) - Universidade Estadual Paulista "Júlio de Mesquita Filho", Jaboticabal, 1991.

EUBA NETO, M.; PEREIRA, W.E.; SOUTO, J.S.; ARRIEL, N.H.C. Crescimento e produtividade de gergelim em neossolo flúvico em função de adubação orgânica e mineral. Revista Ceres, Viçosa, v. 63, n. 4, p. 568-575, 2016.

IJLAL, Z.; TANVEER, A.; SAFDAR, M.E.; AZIZ, A.; ASHRAF, M.; AKHTAR, N.; ATIF, F.A.; ALI, A.; MAQBOOL, M. Effects of weed crop competition period on weeds and yield and yield components of sesame (Sesamum indicum L.). Pakistan Journal of Weed Science Re- search, Peshawar, v. 17, n. 1, p. 51-63, 2011.

ISMAIL, B.S.; TAN, P.W.; CHUAH, T.S. Assessment of the potential allelopathic effects of Pennisetum purpureum Schumach. on the germination and growth of Eleusine indica (L.) Gaertn. Sains Malaysiana, Bangi, v. 44, n. 2, p. 269-274, 2015.

KISSMANN, K.G.; GROTH, D. Plantas infestantes e nocivas. 2. ed. São Paulo: BASF, 1997.

MORAES, P.V.D.de; AGOSTINETTO, D.; PONAZZO, L.E.P.; BRANDOLT, R.R.; TIRONI, S.P.; OLIVEIRA, C.; MARKUS, C. Efeito alelopático de plantas de cobertura, na superfície ou incorporadas ao solo, no controle de picãopreto. Revista da FZVA, Uruguaiana, v. 7, n. 1, p. 51-67, 2010.

NORHAFIZAH, M.Z.; ISMAIL, B.S.; CHUAH, T.S. Herbical activity of $P$. purpureum (Napier grass). African Journal of Biotechnology, Nairobi, v. 11, n. 23, p. 6269-6273, 2012.

PERIN, A.; CRUVINEL, D.J.; SILVA, J.W.S. Desempenho do gergelim em função da adubação NPK e do nível de fertilidade do solo. Acta Scientiarum Agronomy, Maringá, v. 32, n. 1, p. $93-98,2010$.

PINTO, S.M.; DINIZ, A.L.; ARRIEL, N.H.C.; COSTA, F.B. da. Produtividade das cultivares de gergelim de frutos semi-indeiscentes e indeiscentes. Revista de Biologia e Farmácia, Campina Grande, v. 10, p. 88-92, 2014.

PITELLI, R.A.; DURIGAN, J.C. Ecologia das plantas daninhas no sistema plantio direto. In: ROSSELLO, R.D. Siembra directa en el Cono Sur. Montevideo: PROCISUR, 2001. p. 203-210.

QUEIROGA, V.P.; SILVA, O.R.R.F. Tecnologias utilizadas no cultivo do gergelim mecanizado. Campina Grande: Embrapa-CNPA, 2008. (Série Documentos, n. 203).

THEISEN, G.; VIDAL, R.A.; FLECK, N.G. Redução da infestação de Brachiaria plantaginea em soja pela cobertura do solo com palha de aveia-preta. Pesquisa Agropecuária Brasileira, Brasília, v. 35, n. 4, p. 753-756, 2000. 